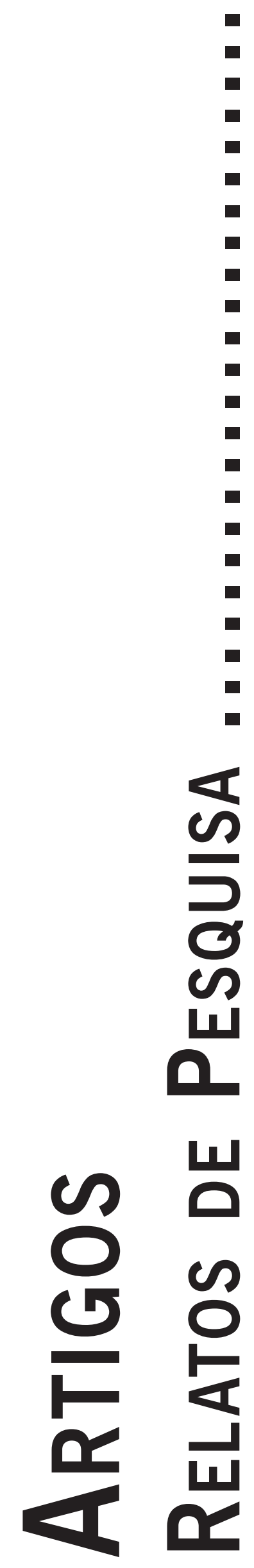




\title{
ATUAÇÃO DO PSICÓLOGO NO CRAS: UMA ANÁLISE FENOMENOLÓGICO-EMPÍRICA
}

\author{
Actuación del Psicólogo en el CRAS: un Analisis Fenomenológico-empirico \\ Psychology Practice in the CRAS: a Phenomenological Empirical analysis
}

Tatyanne Couto Flor

Tоммy AкIRA Gото

\begin{abstract}
Resumo: O Sistema Único de Assistência Social (SUAS) foi implantado no Brasil mediante a necessidade de atender as famílias que vivem em situação de vulnerabilidade social, tendo no nível básico o Centro de Referência de Assistência Social (CRAS). Esse trabalho, desenvolvido a partir da pesquisa de iniciação cientifica (2012-2013), visa identificar a atuação do psicólogo no CRAS da cidade de Uberlândia/MG. A partir do método fenomenológico empírico de Amedeo Giorgi foram realizadas entrevistas com as psicólogas dos CRAS, cuja finalidade foi identificar os significados dessa atuação. O método fenomenológico empírico utilizado divide-se em quatro passos: 1) estabelecer o sentido geral; 2) determinação das unidades de significado; 3) transformação das unidades de significado em expressões de caráter psicológico; 4) determinação da estrutura geral de significados psicológicos. A partir da obtenção dos relatos de experiência encontraram-se os aspectos comuns em todas as entrevistas: todas as colaboradoras apreciam trabalhar no CRAS; percebem que o trabalho tem limitações e dificuldades; descrevem a rotina de trabalho dando ênfase na visita domiciliar; identificam as suas atuações como atendimento individual, psicossocial e em grupo; têm consciência que não é possível realizar atendimentos psicoterapêuticos; identificam o atendimento psicológico como psicossocial; percebem que o trabalho em grupo apresenta muitas dificuldades; e por fim, sentem a necessidade de uma sistematização do trabalho.
\end{abstract}

Palavras-chave: SUAS; Políticas públicas; Atuação do psicólogo; Análise fenomenológico-empírico.

Abstract: The Social Assistance System (ITS) was implemented in Brazil by the need to meet the families living in social vulnerability situation, having at the basic level the Centre of reference of Social Assistance (CRAS). This work, developed from the research of scientific initiation (2012-2013) aims to identify the role of the psychologist at CRAS city of Uberlândia/MG. From the empirical phenomenological method of Amedeo Giorgi were carried out interviews with the psychologists of the CRAS, whose purpose was to identify the meanings of this Act. The empirical phenomenological method used is divided into four steps: 1) establish the general sense; 2) determination of units of meaning; 3) transformation of units of meaning in expressions of psychological character; 4) determination of the general structure of psychological meanings. From the obtaining of reports from experience met the commonality in all the interviews: all employees enjoy working in the CRAS; realize that the work has limitations and difficulties; describe the daily routine of work giving emphasis on home visit; identify your performances as individual assistance, psychosocial and group; are you aware that you cannot perform psychotherapy sessions; identify the psychological care and psychosocial; realize that the group work presents many difficulties; and finally, feel the need for a systematization of labor.

Keywords: Public policies; Role of the psychologist; Phenomenological analysis-empirical.

Resumen: El Sistema Único de Asistencia Social (SUAS) fue implantado en Brasil por la necesidad de atender a las familias que viven en situaciones de vulnerabilidad social, teniendo en el nivel básico el Centro de Referencia de Asistencia Social (CRAS). Ese trabajo intenta identificar la actuación del psicólogo en el CRAS de la ciudad de Uberlândia/MG. Partiendo del método fenomenológico empírico de Amedeo Giorgi fueran hechas entrevistas com as psicólogos de los CRAS, cuya intención fue identificar los significados de la actuación. El método fenomenológico empírico usando está dividido en cuatro etapas: 1) establecer el sentido general; 2) determinación de las unidades de significado; 3) trasformación de las unidades de significado en expresiones de carácter psicológico; 4) determinación de la estructura general de significados psicológicos. Partiendo de la obtención de los relatos de experiencia se encuentran los aspectos comunes en todas las entrevistas: todas las colaboradoras aprecian trabajar en el CRAS; perciben que el trabajo tiene límites y dificultades; describen la rutina de trabajo y ponen énfasis en la visita domiciliar; apuntan sus actuaciones como atendimiento individual, psicosocial y en grupo; tiene consciencia que no es posible realizar atendimientos psicoterapéuticos; apuntan el atendimiento psicológico como psicosocial; perciben que el trabajo en grupo presenta muchas dificultades; y por último, sienten como necesidad una sistematización del trabajo.

Palabras clave: SUAS; Politicas publicas; Atuación del psicólogo; Analisis fenomenológico-empírico. 


\section{Questões preliminares}

A psicologia brasileira vem sofrendo mudanças em seu modo de atuar e de entender o ser humano e uma das causas disso está na inserção das políticas públicas na área da Psicologia. Dessas políticas públicas, destaca-se então o campo do Desenvolvimento Social. Em verdade, foi com as mudanças nas políticas e sociais brasileiras e com elas a ampliação ao atendimento das famílias que estão em situação de pobreza, desigualdade e marginalidade social, por intermédio do Ministério do Desenvolvimento Social (MDS), que foi criado e implantado o Sistema Único de Assistência Social (SUAS). Na elaboração das estratégias e projetos sociais no SUAS, foi-se ampliando os recursos técnicos e humanos, a qual o psicólogo foi incorporado a fazer parte da equipe responsável para atender tais famílias (BRASIL, 2006).

A partir de 1988, a Assistência Social brasileira foi situada como política que integra o sistema brasileiro de seguridade social. Tendo em vista que em 1993 entrou em vigor a Lei Orgânica de Assistência Social (LOAS) que legitimou a assistência social como política pública, garantindo assim os direitos de cidadania da população. A Política Nacional de Assistência Social (PNAS), promulgada em 1995, foi outro marco legal importante já que a mesma define as funções, ações, usuários dos serviços, prioridades e algumas diretrizes. Tal política foi sendo aprimorada tendo uma última revisão em 2004 (BRASIL, 2006).

O Sistema Único de Assistência Social - o SUAS, foi implantado em 2005 no território brasileiro como política pública de Estado, que propõe um novo modelo de gestão da assistência social, pautado em um olhar que busca entender as necessidades humanas de forma global e particular, contextualizando o sujeito integral. A Norma Operacional Básica do SUAS avalia que a diversidade de necessidades sociais carece de respostas públicas diferentes. Devido a isso, o SUAS estabelece dois níveis de proteção social, organizados conforme sua complexidade sendo um básico - de caráter preventivo, e o outro especial, para atender os casos de média e alta complexidade que implicam violação de direitos (BRASIL, 2006a).

A Proteção Social Básica, prevista na Política de Assistência Social em 2004 (PNAS/2004) busca prevenir situações de vulnerabilidade ao desenvolver potencialidades dos usuários, dos vínculos familiares e comunitários. Para isso faz-se um diagnóstico do território a fim de criar serviços, programas, projetos destinados à população que se submete a situações de pobreza, privação e fragilidade de vínculos afetivos, sejam eles relacionais ou de pertencimento social (discriminação etária, étnica, de gênero, por deficiência e outras).

Na Proteção Social Básica se encontra o Centro de Referência de Assistência Social (CRAS), cujo espaço físico público atende as famílias para a garantia de atenção integral as mesmas, cumprindo a proteção social básica (BRASIL, 2006a). O CRAS é o local responsável pela execução do Programa de Atendimento Integral à Família (PAIF) o qual garante recursos financeiros, diretrizes e metodologia para que o centro funcione de acordo com o previsto. A equipe mínima multiprofissional do CRAS é composta por assistente social, psicólogo e outros profissionais que possuem formação compatível com a intervenção social do PAIF (BRASIL, 2006a).

Segundo Botarelli (2008), a inserção do psicólogo no corpo técnico do CRAS foi instituída para que este profissional seja capaz de "intervir nos processos de sofrimento instalados na comunidade e conectar as necessidades dos sujeitos, com ações de desnaturalização da violação de direitos" (Botarelli, 2008, p. 16). Por conseguinte, utilizando de diferentes metodologias e formas de atuação, espera-se que tal profissional procure criar alianças e espaços de transformação, onde a rede de apoio às famílias e os grupos comunitários se mobilizem.

Ainda, o PAIF tem o papel de promover segurança de rendimento, acolhida, autonomia, convívio familiar e comunitário, assim como sobrevivência a outros riscos. Alguns dos serviços oferecidos por tal programa são: Serviços Socioeducativo geracionais, intergeracionais e com famílias; Reabilitação na comunidade; Projetos e Programas de Enfrentamento à Pobreza; Projetos e Programas de Enfrentamento à Fome entre outros. O CRAS tem como prioridade 0 atendimento às famílias, portanto mesmo que alguns serviços não sejam oferecidos nesse local deve-se ter um encaminhamento devido (BRASIL, 2006a).

No que ser refere à implantação física dos CRAS, a orientação é que aconteça segundo o porte dos municípios. Assim, segundo a NOB/SUAS (BRASIL, 2005) a implantação deve ser de:

- Pequeno porte I: município de até 20.000 habitantes/ 5.000 famílias - mínimo de 1 CRAS para até 2.500 famílias referenciadas;

- Pequeno porte II: município de 20.001 a 50.000 habitantes/ de 5.000 a 10.000 famílias - mínimo de 1 CRAS para até 3.500 famílias referenciadas;

- Médio porte: município de 50.001 a 100.000 habitantes/ de 10.000 a 25.000 famílias - mínimo de 2 CRAS cada um para até 5.000 famílias referenciadas;

- Grande porte: município de 100.001 a 900.000 habitantes/ de 25.000 a 250.000 famílias - mínimo de 4 CRAS cada um para até 5.000 famílias referenciadas;

- Metrópole: município de mais de 900.000 habitantes/mais de 250.000 famílias - mínimo de 8 CRAS cada um para até 5.000 famílias referenciadas; 


\section{A implantação do CRAS no município de Uberlân- dia/Minas Gerais}

A implantação do CRAS no município de Uberlândia, Minas Gerais, consolidou-se no ano de 2005 pela Secretaria Municipal do Trabalho e Desenvolvimento Social. Esse centros foram instalados no mesmo espaço físico que os Postos Integrados de Segurança e Cidadania (PISC's). Ainda, deve-se destacar que o nome atribuído ao serviço difere de acordo com as gestões municipais. Os locais de atendimento foram chamados na gestão anterior de "Casa da Família", porém na gestão atual o nome dado é CRAS, conforme o SUAS.

Até meados do ano de 2013, os CRAS contaram com sete (07) unidades em funcionamento, distribuídos em bairros considerados locais de vulnerabilidade social, sendo eles: Jardim Brasília, Mansour, Morumbi, São Jorge, Jardim Célia, Custódio Pereira e Marta Helena. As equipes de trabalho são compostas por coordenadores, assistentes sociais, psicólogos, técnicos de nível médio, monitor social, agentes de serviços gerais e assistentes administrativos. A distribuição dos diferentes trabalhadores é diversificada para cada CRAS, dependendo da demanda e situação de vulnerabilidade. Assim, por exemplo, no que diz respeito ao cargo de psicólogo, o serviço contava até meados de 2013 com sete (07) psicólogos que faziam parte da equipe, sendo que um dos psicólogos atendia em dois CRAS.

Para entender melhor a atuação do psicólogo no CRAS em Uberlândia, objetivo dessa pesquisa, é fundamental identificar as diretrizes e referências técnicas, estabelecido pelo Centro de Referência em Psicologia e Políticas Públicas (CREPOP) criado pelo CFP em 2006. O CREPOP tem como objetivo nortear a atuação do psicólogo nas políticas públicas, consolidando a produção de referência para a atuação do mesmo em tais políticas, realizando pesquisas multicêntricas coordenadas pelo país e criando documentos de referência para a atuação profissional nesse campo.

\section{A atuação do psicólogo no CRAS: diretrizes, refe- rências e práticas}

Partindo do entendimento do Conselho Federal de Psicologia que "políticas públicas são um conjunto de ações coletivas geridas e implementadas pelo Estado, que devem estar voltadas para a garantia de direitos sociais, norteando-se pelos princípios da impessoalidade, universalidade, economia e racionalidade e tendendo a dialogar com o sujeito cidadão" (CFP, 2007, p. 17), o psicólogo no CRAS tem por finalidade fazer com que os usuários sejam sujeitos de direitos, além de fortalecer tais políticas. Para isso, ele deve ter como foco em sua atuação a dimensão subjetiva dos indivíduos para que sejam autônomos e cidadãos. Por isso, a oferta de apoio psicológico na cons- trução de novos significados sociais e existenciais é um recurso importante nas políticas públicas.

Nesse sentido, a Psicologia nesse espaço deve identificar as principais demandas psicossociais dos usuários de modo que se afaste do modelo assistencialista, o qual entende os sujeitos como impotentes e que "precisam de ajuda". Assim, é imprescindível compreender e identificar a demanda dos sujeitos a partir de seu contexto histórico, social e pessoal para que a intervenção psicológica seja efetiva, juntamente com o planejamento dos outros profissionais inseridos no CRAS.

Para nortear o trabalho do psicólogo, o Centro de Referência em Psicologia e Políticas Públicas (CREPOP), estabeleceu alguns princípios gerais a respeito da prática do psicólogo no CRAS, sendo eles:

1. Atuar em consonância com as diretrizes e objetivos da PNAS e da Proteção Social Básica (PSB), cooperando para a efetivação das políticas públicas de desenvolvimento social e para a construção de sujeitos cidadãos; 2. Atuar de modo integrado à perspectiva interdisciplinar, em especial nas interfaces entre a Psicologia e o Serviço Social, buscando a interação de saberes e a complementação de ações, com vistas à maior resolutividade dos serviços oferecidos; 3 . Atuar de forma integrada com o contexto local, com a realidade municipal e territorial, fundamentada em seus aspectos sociais, políticos, econômicos e culturais; 4. Atuar baseado na leitura e inserção no tecido comunitário, para melhor compreendê-lo, e intervir junto aos seus moradores; 5 . Atuar para identificar e potencializar os recursos psicossociais, tanto individuais como coletivos, realizando intervenções nos âmbitos individual, familiar, grupal e comunitário; 6. Atuar a partir do diálogo entre o saber popular e o saber científico da Psicologia, valorizando as expectativas, experiências e conhecimentos na proposição de ações; 7. Atuar para favorecer processos e espaços de participação social, mobilização social e organização comunitária,contribuindo para o exercício da cidadania ativa, autonomia e controle social, evitando a cronificação da situação de vulnerabilidade; 8. Manter-se em permanente processo de formação profissional,buscando a construção de práticas contextualizadas e coletivas; 9 . Atuar com prioridade de atendimento aos casos e situações de maior vulnerabilidade e risco psicossocial; 10. Atuar para além dos settings convencionais, em espaços adequados e viáveis ao desenvolvimento das ações, nas instalações do CRAS, da rede socioassistencial e da comunidade em geral. (CFP, 2007, p. 20-21)

Com o intuito de compreender e analisar como os psicólogos significam seu trabalho no CRAS, dada às orientações estabelecidas, o CREPOP realizou uma pesquisa no estado de Minas Gerais. Para isso, mapearam os 
CRAS e suas equipes de referência, aplicaram um questionário on line e realizaram algumas reuniões abertas e grupos focais. Essa pesquisa teve como objetivo entender o lugar que o psicólogo ocupa a partir do que está previsto na política do SUAS (CRP-04, 2011). A pesquisa dividiu em categorias as palavras-chaves ou conceitos comuns nas discussões dos grupos focais, sendo eles: a) a identidade profissional em questão; b) vulnerabilidade e territorialização; c) acompanhamento familiar, grupo e atendimento individual como dispositivos do CRAS; d) gestão e autonomia do trabalhador; e) sobre registros e relatórios.

$\mathrm{O}$ primeiro aspecto tratado se diz respeito à identidade profissional em questão, resultando em falas que afirmaram que o psicólogo no CRAS não é reconhecido como tal pelos outros profissionais, pelos usuários ou até mesmo por eles mesmos. Outras questões referentes a esse aspecto são: 1) a dificuldade de distinguir a identidade/função do psicólogo com a identidade/função do assistente social e o trabalho interdisciplinar 2) imprecisão nas diretrizes referentes ao trabalho do psicólogo, consequentemente dificuldade de aplicá-las nos CRAS; 3) lacunas na formação acadêmica diante das políticas públicas, especial a do SUAS; 4) falta de referência no trabalho por não ser adequado a concepção de clínica clássica (CRP-04, 2011).

As demais categorias analisadas se referem aos conceitos importantes no trabalho do psicólogo no CRAS como: vulnerabilidade e territorialização, de modo que nos grupos focais discutiram o entendimento desses conceitos; os modos de intervenção profissional tais como acompanhamento familiar, grupo e atendimento individual, no qual mostrou que os psicólogos muitas vezes querem reproduzir a prática psicoterápica ou na tentativa de intervirem não compreendem a real demanda da população. Foram analisadas ainda, as condições de trabalho do psicólogo, sua autonomia e como o serviço é gerenciado, aspecto tão importante nesse contexto já que a gestão é o que possibilita ações efetivas (CRP-04, 2011).

A pesquisa conclui de modo geral que o SUAS vivencia as mesmas dificuldades de outros setores públicos, como a persistência do clientelismo e assistencialismo. Além das práticas dos psicólogos, juntamente com a gestão que muitas vezes não estão condizentes com o marco normativo dessa política. Outro aspecto pertinente é que na proteção básica não há ainda o desenvolvimento da autonomia dos trabalhadores e usuários. E por fim, os psicólogos enfatizam a necessidade de receber diretrizes mais detalhadas de como atuarem nesses espaços, porém conforme esses "pedidos" nota-se que tais profissionais têm uma percepção acrítica frente à metodologia utilizada e forte desconsideração da historicidade que permeia a vulnerabilidade social, destituindo inclusive a autonomia de seu trabalho (CRP-04, 2011).

Diante desses primeiros resultados, pode-se afirmar que as questões como a formação acadêmica do psicólogo brasileiro, a construção de novas práticas profissionais, a inserção da Psicologia no campo das políticas públicas e a elaboração de teorias e conceitos permeados por um novo entendimento de subjetivação são imprescindíveis para a discussão dessa pesquisa. Sobre essa questão, Ferreira Neto (2004) faz uma análise da Psicologia no Brasil, na qual relata que até a década de 1990 a formação em psicologia estava fundamentalmente baseada na ideia de áreas de atuação específicas, tendo maior relevância três áreas: a clínica, a escolar e a industrial.

Segundo o autor, a área que teve maior destaque foi a clínica psicoterapêutica, sendo mais evidenciada nos currículos (maior carga horária) e, consequentemente mais presente no imaginário social da profissão. Tal formação recebeu críticas pertinentes - hoje presente nas mudanças promovidas pelas Diretrizes Curriculares Nacionais para os cursos de graduação em Psicologia (Brasil, 2011) - por considerá-la como tecnicista e fragmentada e que reproduz conhecimentos estrangeiros com discussões mínimas ou inexistentes da realidade brasileira. Além de a área clínica psicoterapêutica ser voltada para as classes média e alta da sociedade, desconsiderando assim o maior contingente populacional, ou seja, as classes populares (Ferreira Neto, 2011).

Para o maior entendimento a respeito das práticas psicológicas no contexto brasileiro é significativo resgatar a concepção de clínica psicológica, em especial a psicoterapêutica. A prática psicológica sempre foi calcada na psicoterapia e psicodiagnóstico tradicional, na qual o psicólogo se constitui como um profissional liberal que utiliza técnicas e teorias para um indivíduo abstrato, universal e não histórico. A partir da metade da década de 1970 surgem movimentos sociais e políticos contrários à ditadura militar e desde então, se passou a problematizar os âmbitos da saúde, educação e ação social. Nesse contexto de discussão e mudanças, a Psicologia não se manteve ilesa sendo que o psicólogo passou a atuar nas camadas populares (Ferreira Neto, 2004).

Um número crescente de psicólogos assalariados em órgãos públicos, e diante de uma população que até o momento nunca havia recebido sua assistência, percebem-se defasados em sua formação. Recebem uma "clientela" cujo modo de expressão do sofrimento não se apresenta numa linguagem psicológica que vai além da menção a um "problema de nervos"; atuam onde sua própria categoria profissional é pouco conhecida e, com frequência, confundida com a referência majoritária ao médico; atendem pessoas cujo único auxilio técnico-oficial, recebido até então sempre foi exclusivamente medicamentoso, administrado em consultas de curtíssima duração. Essas condições, entre outras, estabeleciam uma clínica distinta da aprendida nos bancos das faculdades, e nos estágios e nos ambulatórios das escolas até esse tempo (Ferreira Neto, 2004, p. 91-92). 
As novas concepções dos modos de atuação profissional e da clínica psicológica permitiram, e ainda permitem, uma expansão do campo clínico psicoterapêutico para a população de baixa renda no qual o psicólogo pôde repensar o sujeito de modo contextualizado. A expansão do campo clínico no âmbito social, repensando o sujeito e sugerindo novo fazeres, pode ser obervado, por exemplo, nos trabalhos de Goto e Saulo (2009), Goto e Almeida (2011) e Goto e Ribeiro (2012), que apresentam propostas efetivas de práticas clínico-sociais que abrangem tanto a formação quanto a atuação do profissional no SUAS.

Os referenciais teóricos passaram a ser repensados, fazendo com que os psicólogos começassem a reconhecer a importância de produções teóricas e práticas de acordo com o contexto brasileiro, além da relevância de trabalhos multidisciplinares. Entretanto, concepções baseadas no assistencialismo e de adaptação do sujeito ao meio ainda é muito presente, além de o termo social muitas vezes ser entendido como sinônimo de pobreza. Ferreira Neto (2004) defende que as mudanças ocorridas correspondem mais com mudanças técnicas e de empregabilidade, do que alterações significativas de sujeito e da concepção de subjetividade.

Como já foi discutida, a inserção do psicólogo no âmbito das políticas públicas não aconteceu devido a uma reflexão política que concluiu que esse profissional necessitava atuar para além dos consultórios clínicos liberais, mas sim pelas mudanças sociais no Brasil, principalmente após a queda do regime militar e uma maior contratação de "trabalhadores sociais" nessas políticas instituídas no neoliberalismo. Assim, para se efetivar ações ético-políticas diferenciadas nas políticas sociais não basta abandonar a concepção clássica de clínica, mas abdicar da posição ingênua e acrítica a respeito dos mecanismos de dominação que o sistema atual estabelece, além de diagnosticar tais aspectos no local de atuação e não se submeter exclusivamente a normas e técnicas de atuação profissional.

Uma vez que as práticas psicológicas necessitaram ser repensadas nas políticas públicas, a concepção de subjetividade que permeia tais práticas também passou ser analisada e questionada. Yamamoto e Oliveira (2010, citado por Ferreira Neto, 2011) defendem que a concepção única e exclusiva de sujeito psicológico não é admissível nos desafios encontrados no CRAS, por exemplo. Portanto, o dualismo cartesiano, presente em muitas concepções da psicologia, entre sujeito (interiorioridade) e objeto (exterioridade), está obsoleto. A noção de que a identidade é formada apenas pelo mundo interno e como o indivíduo elabora as experiências cede lugar a ideia de processo, no qual a transformação é permanente e a constituição é plural a partir da exterioridade. Como afirmam Berger e Luckmann, a vida cotidiana "apresenta-se como uma realidade interpretada pelos homens e subjetivamente dotada de sentido para eles na medida em que forma um mundo coerente" (Berger \& Luckmann, 1985, p. 35). Assim, a subjetividade deve ser entendida como uma construção da praxis históricas e geográficas e do sentido compartilhado, ainda que leve em conta o contexto urbano e que considere a ideia de território, entendido por Ferreira Neto (2001) como "potência coletiva de transformação", destacando inclusive os saberes populares.

Frente a isso, já são consideráveis as inúmeras provocações cotidianas colocadas aos psicólogos que atuam nos CRAS, tais como: empreender uma prática interdisciplinar com os profissionais que abarcam a Assistência Social, principalmente o Serviço Social; intervir de modo ético-político em situações de sofrimento e falta de recursos sociais/ políticos; enfrentar os atravessamentos institucionais ou a falta de funcionamento da rede de serviço; entender e seguir o arcabouço jurídico que permeia a Assistência Social a fim de se posicionar como profissional da área pública, dentre outras (Araujo, 2010). Entretanto, um ponto a se considerar diante todos esses questionamentos exigidos aos psicólogos é se a formação acadêmica desse profissional oferece possibilidades para que o mesmo atue de modo competente e ético nessa área.

É importante destacar que o psicólogo poderia utilizar de recursos bem-sucedidos advindos das áreas que sua atuação já é mais consolidada como a saúde, a educação, a comunitária ou até mesmo a clínica (partindo do pressuposto que atendimentos podem ser terapêuticos mesmo não sendo no modelo de psicoterapia tradicional), tendo como propósito a constante indagação sobre sua prática cotidiana, evitando dessa forma repetir procedimentos de modo determinista e adaptativo, na busca de legitimar sua presença no CRAS (Botarelli, 2008).

\section{Metodologia}

Como dito anteriormente, o objetivo dessa pesquisa, realizada como Iniciação Científica na Universidade Federal de Uberlândia, foi compreender a atuação dos psicólogos dos CRAS no município de Uberlândia/Minas Gerais. Para isso foi desenvolvida uma pesquisa qualitativa do tipo fenomenológico-empírico. Segundo Martins e Bicudo (2005), a fundamentação fenomenológica trabalha estritamente ligada ao fenômeno. Tal método propõe uma análise das intuições e não no modo objetivo, partindo do ângulo do sentido que tais fenômenos têm para o sujeito que os vivem (Nasser, 2008). No caso dessa pesquisa, ela se remete a atuação do psicólogo partindo da vivência e percepção das colaboradoras.

Para a obtenção dos relatos, foram realizadas entrevistas conduzidas por uma única pergunta orientadora: "Para você como é a atuação do psicólogo no CRAS?". A escolha de uma pergunta ampla se pauta no entendimento de Nasser que defende que: 
as questões são, geralmente, amplas e abertas a fim de deixar o sujeito exprimir abundantemente seu ponto de vista. O que se pretende obter é uma descrição concreta e detalhada da experiência e dos atos do sujeito, que seja tão fiel quanto possível ao que ocorreu, tal como o viveu (Nasser, 2008, p. 398).

Sendo assim, buscou-se ouvir os psicólogos sem uma compreensão prévia do relato dos mesmos, entendendo que a pesquisa não é estipulada pelo pesquisador e sim pelos sujeitos colaboradores. Ainda, de acordo com Giorgi (2001), o método fenomenológico contempla os requisitos científicos já que produz conhecimento metódico, sistemático, crítico e com vigor subjetivo, além de abarcar os requisitos psicológicos por analisar as descrições em uma perspectiva psicológica, buscando essências psicológicas.

Segundo Giorgi e Sousa (2010), no método fenomenológico aplicado à Psicologia, o investigador busca descrições de outros sujeitos para o seu estudo. Após isso, desenvolve a redução fenomenológico-psicológica adotando um aspecto psicológico sobre o tema estudado. Por fim, o pesquisador busca estabelecer a essência do objeto de estudo por meio da variação livre imaginativa onde se utiliza da análise eidética. O resultado final da análise das entrevistas é fundamentado pelos significados psicológicos, discriminados pelo investigador, entendendo o que os colaboradores da pesquisa não explicitaram diretamente.

Nesse processo, o método é descritivo de modo que o resultado final do processo de análise da entrevista reflete uma "descrição em síntese dos significados psicológicos essenciais da experiência dos participantes da investigação” (Giorgi \& Sousa, 2010, p. 76). Após utilizar a variação livre imaginativa em relação aos significados elaborados da entrevista, o pesquisador apresenta os constituintes-chave os quais compõem a descrição da estrutura da experiência.

Pode-se afirmar que o método fenomenológico consiste em: redução fenomenológica, descrição e busca das essências. Em relação à redução fenomenológica, Nasser (2008) defende que é necessário excluir os conhecimentos dados como anteriores relativos ao fenômeno, com o intuito de apreendê-lo em toda sua inocência e descrevêlo assim como se tem a intuição do mesmo. Além disso, é imprescindível considerar o que é dado pelo sujeito ou pelo fenômeno tal como se aparece. Tal redução rompe com a atitude natural. Na descrição permite-se que ao utilizar a linguagem é possível comunicar com os outros a respeito dos objetos da consciência, "exatamente de modo como eles se apresentam” (Nasser, 2008).

Tendo a finalidade de compreender a atuação do psicólogo no CRAS, os participantes dessa pesquisa foram os profissionais psicólogos dos CRAS do município de Uberlândia/ MG até o ano de 2013, sendo constituído até então de seis (06) psicólogos entrevistados, pois um dos profissionais havia sido convocado para trabalhar no CRAS há menos de um mês.

Após a aprovação do projeto de pesquisa pelo Comitê de Ética em Pesquisa da Universidade Federal de Uberlândia (CAAE: 12338813.2.0000.5152), realizou-se o contato com os seis psicólogos dos CRAS de Uberlândia/ Minas Gerais. Foi explicado aos colaboradores que tal pesquisa tem como objetivo compreender a atuação dos psicólogos no CRAS, contando com seus relatos e vivências. Para isso, foram realizadas entrevistas que necessitaram ser gravadas e transcritas na íntegra, após a assinatura de Termo de Consentimento Livre e Esclarecido. É importante destacar que foi garantido o anonimato dos colaboradores.

O material proporcionado foi diversas vezes lido, procurando sempre não perder o todo, ou seja, o norteador da questão central. Ao mesmo tempo, foi dado espaço para que cada descrição remeta a um reviver de situações da experiência, pois "esses dados obtidos são as situações vividas que foram conscientemente tematizadas pelo sujeito" (Martins \& Bicudo, 2005, p. 97). Assim, foi a partir delas que se iniciou a análise para a compreensão do fenômeno estudado.

A partir da obtenção dos relatos de experiência e da transcrição na íntegra, o método se divide em quatro passos: $1^{\circ}$ ) estabelecer o sentido geral; $2^{\circ}$ ) determinação das partes (divisão em unidades de significado); $3^{\circ}$ ) transformação das unidades de significado em expressões de caráter psicológico; $4^{\circ}$ ) determinação da estrutura geral de significados psicológicos- invariantes (Giorgi \& Souza, 2010).

Primeiramente, ao estabelecer o sentido do todo, o objetivo foi apreender o sentido geral do relato. Nesse passo os investigadores leram tranquilamente a transcrição da entrevista, se colocando na atitude da redução fenomenológica (abdicando de hipóteses interpretativas ou focar em partes fundamentais). Portanto, o objetivo foi "obter um sentido da experiência na sua globalidade” (Giorgi \& Sousa, 2010, p. 86).

No segundo passo, determinação das partes, os investigadores apreenderam o sentido geral do relato e retomaram a leitura do mesmo a fim de dividi-lo em partes menores, denominadas unidades de significado, permitindo assim uma análise mais aprofundada. O procedimento nesse passo pretendeu identificar a partir de uma perspectiva psicológica a transição de sentido, ou seja, os investigadores marcaram e identificaram sempre que houvesse uma mudança de sentido no relato, dividindo e definindo as unidades de significados em toda a entrevista. Tal procedimento foi descritivo de modo que considera os significados importantes para o tema de estudo (Giorgi \& Sousa, 2010).

Na transformação das unidades de significado em expressões de caráter psicológico, momento crucial do método, a linguagem cotidiana do sujeito do relato se transformou em expressões que tem como objetivo clarificar 
e explicitar o significado psicológico das descrições do sujeito. O sentido retirado pelos pesquisadores deve ser revelador e psicologicamente explícitos em relação ao tema estudado, retirando os aspectos aleatórios e privados que não clarificam a estrutura essencial dos significados psicológicos (Giorgi \& Sousa, 2010).

No quarto momento do método, os investigadores transformaram as unidades de significado em uma estrutura descritiva geral, na qual "engloba os sentido mais invariantes que pertencem às unidades de significado transformados em linguagem psicológica” (Giorgi \& Sousa, 2010, p. 90). Tal processo de articulação é holístico e de caráter psicológico. O que se destaca é que a estrutura final expresse a rede essencial das relações entre as unidades dando ênfase ao significado psicológico total.

\section{Resultados obtidos: síntese descritiva dos relatos}

Como proposto, a análise dos dados seguiu os procedimentos de Amedeo Giorgi $(2001,2010)$ que foca a identificação das unidades de sentido. Para o autor, a análise fenomenológica envolve: $1^{\circ}$ ) estabelecer o sentido geral; $2^{\circ}$ ) determinação das partes (divisão em unidades de significado); $3^{\circ}$ ) transformação das unidades de significado em expressões de caráter psicológico; $4^{\circ}$ ) determinação da estrutura geral de significados psicológicos (invariantes). Neste estudo, será disponibilizado apenas o quarto passo do método: a determinação da estrutura geral de significados psicológicos. Obtiveram-se, assim, as seguintes sínteses descritivas dos relatos:

Para a colaboradora A atuar no CRAS é muito interessante, gosta e sente gratificante em relação ao seu trabalho, mesmo percebendo certas limitações. Ela entende que a atuação no CRAS é mais difícil por ser preventiva e também pelo modo como a realiza, de maneira individual, psicossocial e em grupo, mas também em conjunto com a assistente social, principalmente nas abordagens domiciliares. Descreve a sua rotina de trabalho que além do atendimento psicológico consta em: fazer visitas, atender as famílias no CRAS, fazer e digitar relatórios e preparar grupos. Ela também defende que o papel do psicólogo no CRAS é orientar e inserir as famílias nos seus direitos, acolher, orientar e levar reflexões, valorizando assim as potencialidades da família. Para isso sempre busca levar questionamentos nas discussões com os usuários do serviço, entendendo que o seu trabalho não é realizar uma psicoterapia, mas sim uma terapia de apoio. Por fim, a entrevistada relata dificuldades no seu trabalho, tais como: dúvidas ainda em relação ao papel do psicólogo no CRAS por parte dos próprios profissionais, por isso defende que é importante ter encontros entre psicólogos dos CRAS para esclarecer tais dúvidas e realizarem práticas semelhantes; a relação com outros profissionais e por fim, a falta de integração da rede como um todo.
A colaboradora $B$ conta que antes de trabalhar no CRAS já tinha conhecimento teórico, leu a respeito da atuação do psicólogo no CRAS e que na época desse estudo não fez sentido por parecer muito "filosófico". Relata que em sua formação acadêmica não teve contato com a política pública do SUAS, mas que atualmente está usando recursos de estágios como grupos, acolhimentos e orientações breves. A entrevistada diz que em relação ao trabalho em conjunto com o assistente social, podem surgir conflitos e que para solucionar isso pensa ser necessário fazer uma separação de ambos os serviços. Ela destaca que não é recomendado realizar atendimentos psicoterapêuticos no CRAS, mas sim orientações breves, porém para isso ela precisa levantar dados e investigar até ter uma ideia do que é o caso para realizar encaminhamentos ou encerrar. Para realizar isso, ela criou instrumentos próprios para a realização do seu trabalho. Na percepção dela as demandas do serviço advém dos encaminhamentos feitos pela rede, dos usuários que procuram o serviço devido ao Bolsa Família e das visitas realizadas com a assistente social. Nas visitas acaba por fazer perguntas genéricas sobre o caso e as realiza apenas quando tem tempo livre. Além disso, a colaboradora relata o quão é importante saber da área de abrangência do CRAS e diferenciar os casos que são de prevenção ou especializados. Ainda, relata que o trabalho em grupo no CRAS é privilegiado pela instituição, porém encontra dificuldades para estabelecer os temas dos grupos, sentido que o horário que é realizado é de difícil acesso para a população e que tais grupos funcionam, em verdade, como palestras. Percebe outras dificuldades na sua atuação, tais como: o cadastro dos usuários do serviço é burocrático; conflitos com outros profissionais e superiores em relação ao trabalho. Por estar a pouco tempo no CRAS busca preencher todo o seu tempo de trabalho e que está gostando de trabalhar nesse local, além de acreditar que o trabalho do psicólogo no CRAS é importante para a população que não tem acesso ao serviço do psicólogo.

O relato da colaboradora $C$ mostra que as demandas de seu serviço têm sido: a espontânea, do encaminhamento do Ministério Público, do poder judiciário, de escolas e do Conselho Tutelar. Afirma que onde ela atua, a procura é menor em relação aos outros CRAS, assim se disponibiliza mais para ir às visitas domiciliares com a assistente social, mesmo como observadora. Diz que ao perceber as vulnerabilidades sociais e emocionais, ela convida as famílias a irem a um acolhimento. Entende que em alguns casos a vulnerabilidade financeira é mais emergencial frente a emocional. Além disso, apesar de seu trabalho ser em equipe (com a assistente social), compreende que existem diferenças importantes. Nos acolhimentos a colaboradora procura entender o caso e se há necessidade de encaminhamentos específicos. Mesmo que orientações superiores e as referências coloquem não ser possível realizar psicoterapia no CRAS, a entrevistada defende que 
nos acolhimentos acha impossível não agir terapeuticamente. Declara também que sente oscilações do trabalho no CRAS de acordo com as diferentes gestões municipais e que a anterior era centralizadora, porém agora está se sentindo mais livre para atuar. Gosta de fazer a primeira orientação para a população e dos trabalhos de grupos. Para se aproximar dos usuários muitas vezes ela faz atividade que não são do psicólogo, porém tem negado fazer o Cadastro Único.

A colaboradora $D$ percebe o CRAS como um campo rico de possibilidades da atuação do psicólogo e que propicia o deslocamento da Psicologia do contexto privado para o contexto comunitário, além de possibilitar que se repense e tenha um novo olhar sobre a psicologia social e as psicopatologias. Nesse sentido, pensa que a criação de novas estratégias de intervenção precisa se modificar, fazendo com que o psicólogo recrie também sua prática. Embora exista uma diretriz única entende que o trabalho no CRAS assume feições diferentes e que para que se possibilite uma maior qualidade de vida para a população, a rede deveria ser mais eficiente e organizada. Na sua prática entende que as estratégias utilizadas para acompanhar as famílias são: atendimento individual, familiar, realização de grupos e visitas domiciliares. No entanto, para ela o território tem papel fundamental numa intervenção mais conjunta e eficaz com as famílias, sendo a busca ativa um recurso importante de ser utilizado para entender melhor as demandas dos usuários. Relata ainda que está tendo dificuldades na organização dos grupos e que na gestão anterior ela não tinha tanta autonomia na sua atuação, que o CRAS exercia o mínimo e que outros profissionais não tinham acesso a esse espaço. Apesar dessas dificuldades relatadas ela tem a expectativa de que nessa nova gestão se possa desempenhar de forma completa as possibilidade do CRAS, além de admitir que gosta de trabalhar nesse espaço. Adverte ainda que os cursos superiores deveriam de apropriar mais sobre o CRAS.

A colaboradora $E$ remete ao seu trabalho no CRAS como uma atuação conjunta com a assistente social, mesmo entendendo que ambos os trabalhos possuam diferenças, inclusive nas visitas domiciliares. Conta que o acolhimento, visitas domiciliares, atendimentos particularizados e os grupos são algumas atividades realizadas na sua atuação. Além disso, relata que as demandas podem ser espontâneas ou encaminhadas por outro setor. Acredita que os grupos permitem um espaço para uma melhor reflexão das situações familiares e são momentos de informação. Em relação ao seu trabalho, descreve o acompanhamento familiar como intervenções contínuas e com objetivos estabelecidos que permitem à família refletir sobre sua realidade, construir novos projetos de vida, transformar suas relações além de prevenir certas situações. Especificamente entende que seu trabalho é criar vínculos com a família. Algumas vezes a população acha que o atendimento vai ser psicoterápico, mas a colaboradora esclarece que seu trabalho é acolher e não realizar uma terapia. Ela admite que tem trabalhado muito no CRAS e que está trabalhando nesse local desde sua implantação. Ela identifica algumas dificuldades sendo elas: o trabalho em grupo, já que a população participa pouco; o espaço físico deste CRAS; e que o acompanhamento familiar deveria ser mais frequente. Por fim, os pontos positivos relatados pela entrevistada foram: acredita que a rede é uma ferramenta importante na divulgação dos grupos; acha que a equipe que trabalha se dá bem; além de gostar de trabalhar no CRAS.

Por fim, a colaboradora $F$ relata que está no CRAS recentemente e que seu contrato é na área de psicologia social. Identifica que desconhecia a atuação do psicólogo até trabalhar nesse local, por isso tal atuação ainda é uma construção. Embora a construção da sua atuação seja sofrida, relata que tal área é muito bonita e gosta de trabalhar no CRAS. Conta que está à procura de referências teóricas já que a própria política do CRAS é recente. Refere-se ao seu trabalho como uma construção de papéis além de traçar interlocuções com outros profissionais da assistência social. A divergência que encontra em relação a sua atuação está na assistência social, principalmente na linguagem, quando, por exemplo, escrevem um relatório juntas. Revela a importância de se olhar o indivíduo/ família no contexto que está inserido, diferenciando do clínico e do social e percebe que aprendeu isso em sua formação acadêmica. Acredita, porém que o trabalho do psicólogo no CRAS não é apenas de olhar o social, mas também de se ter o caráter terapêutico/preventivo, entendendo a dinâmica maior que envolve o indivíduo. Em relação ao trabalho feito com a população ela faz orientações, acompanhamentos, avaliações; utiliza de entrevista para colher o histórico do usuário, mesmo não aplicando testes; além de diferenciar o nível de atendimento da atenção básica para o atendimento clínico contínuo, dando a possibilidade de fazer parceria com outros setores. Nisso, acha importante esclarecer aos usuários que o seu trabalho não é clínico dentro do CRAS. Por fim, sente necessidade de valorizar o trabalho do psicólogo no CRAS e relata que ainda não foi possível realizar uma articulação de todas as psicólogas dos CRAS de Uberlândia para criarem um espaço de troca, de discussão de casos e de supervisões.

\section{Descrição e análise dos invariantes e variantes}

A partir da obtenção dos relatos de experiência, da transcrição na íntegra e da síntese da estrutura geral, encontraram-se alguns aspectos comuns em todas as entrevistas (denominados invariantes) e alguns aspectos que se diferenciaram (denominados variantes). Nesse sentido, retomando a metodologia estabelecida, obtiveram-se nessa pesquisa os seguintes invariantes: a) todas as entrevistadas apreciam e sentem que é gratificante traba- 
lhar no CRAS; b) percebem que o trabalho tem limitações e dificuldades, sendo diferentes em cada CRAS; c) descrevem a rotina de trabalho dando maior ênfase na visita domiciliar; d) identificam as suas atuações como: atendimento individual, psicossocial e em grupo; e) as profissionais têm consciência que não é possível realizar atendimentos psicoterapêuticos, ao mesmo tempo em que pensam que as intervenções são terapêuticas; f) identificam o atendimento psicológico como psicossocial, apesar de relatarem esse atendimento de maneira e concepções diferentes; g) percebem que o trabalho em grupo com a comunidade apresenta muitas dificuldades; e por fim, h) as profissionais sentem a necessidade de uma sistematização do trabalho.

Ribeiro (2013) como proposta de sua pesquisa, analisou as quatro publicações do CFP acerca da atuação do psicólogo no SUAS - 'Parâmetros para a atuação de assistentes sociais e psicólogos (as) na Política de Assistência Social' (CFP \& CFESS, 2007); Referência Técnica para Atuação do(a) Psicólogo(a) no CRAS/SUAS (CFP, 2007); Como os Psicólogos e as Psicólogas podem contribuir para avançar o Sistema Único de Assistência Social (SUAS) - Informações para gestoras e gestores (CFP, 2011); e Referências Técnicas para Prática de Psicólogas(os) no Centro de Referência Especializado da Assistência Social - CREAS (CFP, 2013) -, identificando assim quatro orientações, oito ações, seis problemas e três dilemas vivenciados pelos psicólogos no dia-a-dia do seu trabalho e atuação. Ribeiro (2003, p. 83), sugere Quadro 1:

Assim, comparando os invariantes obtidos em nossa pesquisa com a síntese produzida por Ribeiro (2013), a partir das referências dos documentos, encontram-se presentes, convergentes, os seguintes pontos: 1. Orientação: "Mudança de paradigma acerca da atuação do psicólogo" e "Condições adequadas de trabalho"; 2. Ações: "Atendimentos individuais e/ou familiares", "Intervenções grupais", "Registro de informações", "Ações psicossociais"; 3. Problemas: "Precarização das condições de trabalho", "Complexidade dos casos" e "Papel do Psicólogo"; e por fim, 4. Dilemas: "Teoria X prática”; "Interdisciplinaridade X Identidade Profissional X Sigilo Profissional”. Apesar de termos uma presença significativa dos itens nos relatos dos colaboradores do CRAS de Uberlândia, o que mostra o conhecimento e a identificação da atuação do psicólogo nesse campo, ainda é preci- so descrever os pontos significativos dos relatos a fim de mostrar de que maneira estão ou não vivenciado esses itens em sua atuação.

O primeiro invariante sintetizado como apreciação e gratificação que as colaboradoras da pesquisa relataram ao trabalharem no CRAS, remete a diferentes formas de percepção dessa apreciação (variantes). Diante disso, o gostar do trabalho advém das visitas domiciliares realizadas na atuação das colaboradoras, do atendimento familiar, por ser um campo novo de trabalho para o psicólogo, por ter contato com famílias e até mesmo por realizar trabalhos em grupos.

O segundo invariante obtido a partir dos relatos foi que as colaboradoras percebem que o trabalho apresenta limitações e dificuldades, de modo que é diferente essa percepção em cada relato (variantes). As dificuldades apresentadas foram: há dúvidas do papel do psicólogo no CRAS, tanto por parte dos próprios psicólogos quanto pelos outros profissionais; dificuldades no trabalho em grupo; o acompanhamento familiar deveria ser mais frequente; a falta de articulação entre todos os psicólogos do CRAS; a falta de integração da rede de serviços; o quanto o cadastro do usuário é burocrático; o trabalho realizado no CRAS depende diretamente das gestões municipais ou locais (de cada CRAS), de modo que se houver mudanças nas gestões modificam-se também as "diretrizes" da atuação do psicólogo nesse espaço.

O terceiro invariante é a descrição da rotina de trabalho dos psicólogos no CRAS, a qual perpassa por atividades como: visitas domiciliares, atendimentos particulares ou em grupos, realizar orientações aos usuários dos serviços, fazer acompanhamentos e avaliações dos casos, preparar e realizar grupos e fazer relatórios. A atividade que teve maior destaque nos relatos foram as vistas domiciliares.

Um dos pontos analisados na pesquisa do CREPOP e CRP-04 foi os dispositivos utilizados pelos psicólogos no CRAS: o acompanhamento familiar, os grupos e atendimentos individuais. A respeito do acompanhamento familiar o SUAS orienta que o desenvolvimento de intervenções deve permitir a família refletir sobre a realidade em que vive, construir novos projetos e possibilitar mudanças nas relações, destacando a autonomia e o protagonismo social. Algumas colaboradoras mostraram ter esse conhecimento e embasar sua prá-

Quadro 1: Resultados: Referências Técnicas (RIBEIRO, 2013, p. 83)

\begin{tabular}{|c|c|c|c|c|}
\hline & Orientações & Ações & Problemas & Dilemas \\
\hline 晜 & $\begin{array}{l}\text { 1. Mudança de paradig- } \\
\text { ma acerca da atuação } \\
\text { do psicólogo } \\
\text { 2. Formação Continuada } \\
\text { 3. Participação Política } \\
\text { 4. Condições adequadas } \\
\text { de trabalho }\end{array}$ & $\begin{array}{l}\text { 1. Atendimentos individuais e/ou familiares } \\
\text { 2. Intervenções grupais } \\
\text { 3. Intersetorialidade } \\
\text { 4. Trabalho Interdisciplinar } \\
\text { 5. Articulações coletivas e Participação } \\
\quad \text { política } \\
\text { 6. Registro de informações } \\
\text { 7. Ações psicossociais } \\
\text { 8. Inserção na comunidade }\end{array}$ & $\begin{array}{l}\text { 1. Precarização das condições de } \\
\text { trabalho } \\
\text { 2. Articulação com a rede socioassis- } \\
\text { tencial e demais políticas públicas } \\
\text { 3. Ausência de formação continuada } \\
\text { e avaliação do trabalho } \\
\text { 4. Abuso de poder } \\
\text { 5. Complexidade dos casos } \\
\text { 6. Papel do Psicólogo }\end{array}$ & $\begin{array}{l}\text { 1. Teoria X prática } \\
\text { 2. Interdisciplinaridade X } \\
\text { Identidade Profissional } \\
\text { X Sigilo Profissional } \\
\text { 3. Assistencialismo X Di- } \\
\text { reitos sociais }\end{array}$ \\
\hline
\end{tabular}


tica nessa orientação, destacando a construção do vínculo com a família.

Sobre o quarto invariante pode-se dizer que as colaboradoras remetem a sua atuação no CRAS em atendimento individual no qual é realizado um acolhimento com o sujeito dentro de um setting, atendimento psicossocial onde permeia um olhar voltado para as questões psíquicas e do contexto do sujeito e atendimento em grupo, tanto familiar, quanto os grupos socioeducativos ou preventivos.

Já o quinto invariante encontrado mostra que as psicólogas têm consciência que não é possível realizar atendimentos psicoterapêuticos de acordo com a clínica tradicional, porém acreditam que as intervenções são terapêuticas, baseadas em acolhimentos do sujeito e não em atendimentos psicoterápicos de longa duração. Nesse sentido, elas relatam a importância dos encaminhamentos a parceiros da rede. No CRAS a atuação permeada pelo modelo clínico é questionada, segundo Araujo (2010), pelo fato da demanda quantitativa que o serviço possui por isso o trabalho do grupo é viável nesse espaço. Ainda, Botarelli (2008) afirma que a população entende que o psicólogo no CRAS atenderá com enfoque na saúde mental, porém os profissionais da Psicologia entendem que o atendimento deve ter caráter preventivo, mas precisa distanciar dos moldes psicoterápicos.

Ferreira Neto (2011) atenta que para que as ações sejam ético-políticas. Assim, nas políticas sociais é necessário que o profissional psicólogo vá além das normas técnicas da profissão, que ele abdique da posição ingênua e acrítica a respeito dos mecanismos de dominação atual e diagnostique tais aspectos no território de atuação.

$\mathrm{Na}$ pesquisa do CREPOP e CRP-04 foram relatadas as dificuldades dos psicólogos de estabelecerem um limite entre acompanhamento psicossocial e psicoterapia e, houve pouco consenso sobre essa limitação. O profissional psicólogo fica confuso se pode realizar atendimentos individuais em um serviço em que o trabalho de grupo é primordial além de a população apresentar dificuldades em delimitar o trabalho do psicólogo pelo fato da "imagem social" desse profissional ser permeada pela prática clínica.

As colaboradoras relataram também que o atendimento psicológico se baseia fundamentalmente no aspecto psicossocial. $\mathrm{O}$ entendimento desse atendimento psicossocial foi destacado de diferentes formas já que elas entendem que os sujeitos/ famílias devem ser compreendidos a partir de seu contexto, de sua realidade bem como a partir das potencialidades que apresentam. O psicólogo deve compreender o sujeito tanto na dimensão psicológica quanto na concretude que ele vive, diferenciando o olhar clínico do social. Botarelli (2008) entende que o atendimento psicossocial é primazia do trabalho do psicólogo, pelo fato de que é necessário entender a dinâmica familiar e detectar as carências da população, a fim de encaminhar para um atendimento qualificado da rede.

A reflexão do serviço psicossocial desenvolvido pelos psicólogos foi relatada também na pesquisa do CREPOP e CRP-04, na qual os relatos são de que o psicólogo deve ter um olhar que abarque as questões subjetivas e as concretas relacionadas à vulnerabilidade social, analisando o contexto e as potencialidades dos sujeitos.

As participantes relataram que os grupos realizados no CRAS apresentam dificuldades, apesar de as descreveram de diferentes formas. Os variantes desse aspecto foram: a pouca participação por parte da população nesses grupos; dificuldades em estabelecer temas para os grupos; o horário dos grupos é de difícil acesso para a população; a semelhança dos grupos como palestras; e dificuldades na organização dos mesmos.

Tais dificuldades nos grupos também foram apontadas pela pesquisa de Araujo (2010), na qual ela realizou entrevistas com as psicólogas de diferentes CRAS no Brasil e elas se remetem ao trabalho de grupo no formato de palestras que não atraia a população. Diante disso, elas propõem estratégias de trabalho nos grupos que fogem do modelo de palestra, pois quem irá escolher o tema é a população e o modo de expor o tema proposto é com a participação direta dos usuários do serviço. Além disso, é ressaltado no trabalho de Araujo que os grupos são unidades de privilégio do trabalho do psicólogo já que se acredita que tal profissional tem maiores habilidades de manejo com grupos (Araujo, 2010).

Há também relatos de dificuldades no desenvolvimento de atividade em grupo na pesquisa do CREPOP e CRP-04: a pouca participação nos grupos, a dificuldade em delimitar as demandas da população, delimitar temas para os grupos e a organização em geral. Relatos interessantes dessa pesquisa sobre os grupos foram de alguns psicólogos tentarem tornar esse trabalho mais atrativo para a população como: a oferta de lanches, a realização de eventos, atividades lúdicas, atividades físicas, realização de oficinas.

Outro aspecto diz respeito a não sistematização do trabalho do psicólogo no CRAS. As colaboradoras relataram que têm conhecimento das orientações formais da atuação, porém não existe uma orientação específica de trabalho para cada CRAS, já que as demandas se diferem. Isso proporciona um trabalho sem referências objetivas dessas profissionais, pois não existem reuniões entre os psicólogos dos CRAS, discussões e até mesmo supervisões do fazer psicológico.

Além das variantes mencionadas acima, outros foram observados nos relatos. Um deles foi que as mudanças de gestão municipal fazem o trabalho do psicólogo nos CRAS de Uberlândia oscilar entre centralização de poder por parte da secretaria ou autonomia. Além disso, houve relatos que demonstraram expectativas positivas diante a nova gestão municipal. Araujo (2010) defende que o trabalho no CRAS está estritamente ligado 
as negociações com a gestão pública que coordena esse serviço, de modo que em certos momentos o CRAS pode estar como um serviço que abarque toda a responsabilidade da Assistência Social ou que seu funcionamento seja reduzido, se tornando um espaço que fiscaliza apenas as condicionalidades dos programas ou realizado encaminhamento para outros setores, ambos os modos de funcionamento estão equivocados, segundo a autora.

Deve-se destacar que outro aspecto importante nos relatos foi em relação à formação acadêmica desses profissionais já que as mesmas não proporcionaram um contato com a política pública da Assistência Social, embora houvesse subsídios em relação ao olhar psicossocial e nas práticas realizadas nesse serviço, como atendimentos em grupo.

Essa mesma questão foi também explicitada na pesquisa do CREPOP E CRP-04 que aponta a formação profissional sem o contato na graduação com a política do SUAS. Isso foi percebido no relato de certas colaboradoras dessa pesquisa que apesar da graduação oferecer alguns subsídios para a atuação do psicólogo no CRAS, a falta de conhecimento dessa Lei enquanto estudante de psicologia proporcionou certo desconhecimento sobre o fazer psicológico quando se depararam com o serviço. A colaboradora D fez um apelo em seu relato de que os cursos superiores deveriam se apropriar mais sobre a atuação do psicólogo no CRAS, dando ênfase na importância desse setor para a população.

Outro ponto levantado e que teve significância nos relatos foi em relação à burocratização no serviço como, por exemplo, o Cadastro Único, pois o mesmo é preenchido manualmente nos CRAS. A dificuldade está na mobilidade do documento, pois caso a família mude de endereço, o mesmo deve ser requisitado na prefeitura e preenchido novamente no CRAS da área de abrangência deste endereço do usuário. Fato também mencionado na pesquisa do CREPOP e CRP-04 pelo fato dos psicólogos entenderem o Cadastro único deveria ser preenchido por assistentes sociais e não pelos psicólogos além da burocratização do serviço.

No que se remete ao trabalho do psicólogo no CRAS ele foi caracterizado como preventivo, fato significante no serviço por ser de Proteção Básica. Além disso, houve um relato no qual a psicóloga criou um instrumento para ela registrar os atendimentos realizados. Foi também enfatizado por algumas colaboradoras a especificidade do trabalho do psicólogo comparado ao assistente social. Dentre essas especificidades estão as diferentes formas de ambas atuarem nas visitas domiciliares e as divergências de linguagem quando escrevem um relatório juntas. Em sua pesquisa, Araujo (2010) revela nas falas das entrevistadas certa dicotomização do trabalho do psicólogo e do assistente social, onde o primeiro se responsabiliza pela demanda material da população e o segundo por ouvir o que a população tem a dizer sobre suas necessidades para além do material.
Em relação à identidade profissional do psicólogo na pesquisa do CREPOP e CRP-04 os psicólogos-participantes se preocuparam em esclarecer as especificidades da atuação do fazer psicológico com a assistência social já que os próprios psicólogos, os outros profissionais e até os usuários apresentam a dificuldade em distinguir entre o trabalho de ambos.

O MDS propõe a interdisciplinaridade no CRAS de modo que os profissionais possam construir coletivamente propostas de intervenção que abarquem a situação de vulnerabilidade social apresentada no cotidiano das famílias, afastando a ideia de ações técnicas individualizadas das diferentes formações (BRASIL, 2009a). Portanto é importante que os profissionais se atentem para essa questão onde essa delimitação na atuação não promova o mero isolamento de saberes, mas que respeitem as responsabilidades e competências de cada profissional.

Algumas colaboradoras percebem certas dificuldades de acesso das famílias nos CRAS como: o horário de atendimentos desse serviço ser apenas comercial, os horários em que os grupos são realizados não viabilizam a participação da população e, ainda, a localização dos CRAS que podem ser de uma distância que não permite o fácil acesso ao serviço. Por fim, uma parte significativa das colaboradoras relatou a importância do bom funcionamento da rede de serviços em geral, que deixa a desejar no município.

As queixas trazidas na insuficiência da rede de serviços onde não se consegue programar ações envolvendo a rede, na pesquisa do CREPOP e CRP-04 foram:

baixa autonomia para planejamento; ausência de articuladores de rede, ou então de tempo para eles mesmos se ocuparem disso; ausência de serviços especializados como o CREAS e o CAPS para encaminhamento; ausência de delimitação de um território de abrangência; e entraves ligados à gestão municipal para que o CRAS incentive a participação social (CRP-04, 2011, p. 90).

\section{Considerações finais}

Os relatos dessa pesquisa, recolhidos no ano de 2013, apontam a questão recorrente em outras pesquisas (Botarelli, 2008; Araújo, 2010; Ribeiro, 2013) do caráter processual da prática, atribuições e funções do psicólogo no CRAS. Além disso, pontos mencionados congruentes na pesquisa desenvolvida pelo CREPOP e CRP-04, da síntese dos documentos (Ribeiro, 2013) e da pesquisa atual no município de Uberlândia, mostra o quanto a presença do psicólogo é recente no SUAS e que, apesar do conhecimento de sua atuação, essa política ainda está em processo de implantação e apropriação profissional no Brasil. 
Mesmo sendo uma condição profissional atual, ainda há escassez de estudos acerca dessa temática, o que ressalta ainda mais a importância de discutir a atuação do profissional psicólogo no CRAS e o compartilhamento das experiências formativas relacionadas a essa área. A maioria das publicações encontra-se nos materiais (cartilhas de referência ou pesquisas quantitativas ou qualitativas) que o Conselho Federal e Regional de Psicologia e o Centro de Referência Técnica em Psicologia e Políticas Públicas têm produzido.

$\mathrm{Na}$ pesquisa realizada obteve-se como resultados os seguintes significados comuns da atuação do psicólogo na CRAS: o sentimento de gratidão no trabalho no CRAS; percepção que o trabalho tem limitações e dificuldades, sendo diferentes em cada CRAS; maior ênfase na visita domiciliar; a identificação de suas atuações como: atendimento individual, psicossocial e em grupo; a consciência que não é possível realizar atendimentos psicoterapêuticos tradicionais, ao mesmo tempo em que consideram que as intervenções são terapêuticas; a identificação que o atendimento psicológico deve ser psicossocial, apesar de relatarem esse atendimento de maneira e concepções diferentes; o sentimento de que o trabalho em grupo com a comunidade apresenta muitas dificuldades; e por fim, a necessidade de uma sistematização do trabalho. É importante salientar que com a mudança da gestão municipal promovida pelas eleições de 2012, houve novas contrações de psicólogos (e assistentes sociais) em meados de 2013, aumentando o número de profissionais e de CRAS no município, conforme as normas estabelecidas.

Apesar de ser perceptível nas sínteses comuns dos relatos o conhecimento dos colaboradores dos vários pontos sugeridos pelas Referências, Cartilhas e a identificação dos problemas da formação e atuação a partir da própria experiência, pode-se dizer que ainda falta a apropriação desse conhecimento como fundamento de uma nova prática. Como observa Ribeiro (2013) o desafio da atuação do psicólogo agora está além do conhecimento do campo, ou seja, está no momento de estabelecer e desenvolver novas práticas para estes novos contextos, "práticas que representem uma real mudança de perspectiva da Psicologia em se comprometer socialmente com a maioria da população que sofre as consequências da questão social” (Ribeiro, 2013, p. 106). Ainda, é importante que o psicólogo tenha um comprometimento ético-político, para que as políticas sociais e as redes de apoio sejam efetivamente construídas a partir do que o caso exige.

Tais pressupostos, segundo observado nos relatos obtidos, são dificultados pela pouca formação acadêmica do psicólogo na área das Políticas Públicas; pela falta de sistematização do fazer psicológico e da apropriação de fato do conhecimento das políticas - entendidos aqui como pré-condição de uma nova práxis - e pelo processo de implementação das políticas nos mu- nicípios. Esses parecem ser pontos (formação, atuação e políticas) que acabam gerando a ausência de referências objetivas e práticas, além da insuficiência da rede de serviços. Esses aspectos refletem em um trabalho pouco autônomo por parte desses profissionais, além da escassa participação dos usuários na constituição do próprio serviço.

A formação do psicólogo no SUAS deve ser entendida aqui como mais do que mera inclusão de disciplinas em sua formação, cuja ênfase ainda tem sido "conteudistas" e nem pela identificação dos psicólogos como uma classe de trabalhadores do SUAS; elementos objetivos da formação. Mas, como adverte Stein, está em conceber a formação não apenas como "uma posse externa de conhecimentos e, sim, a forma que a pessoa humana assume sob a influência de múltiplas forças vindas de fora, ou então o processo dessa moldagem” (Stein, 1999, p. 137). Nisso, é preciso admitir a existência de fatores e condições também subjetivas que estão diretamente correlatas às objetivas na formação e atuação do psicólogo. Para isso é fundamental que as concepções de subjetividade e intersubjetividade, como explica Ales Bello (2003), passem a ser entendidas, portanto, como constitutivos da singularidade da pessoa e da comunidade, no sentido de que o exercício da consciência e das escolhas livres, constituam um eixo que pode determinar e formar uma unidade de intenções.

Por fim, para a superação dessas dificuldades é necessário estar sempre revisitando a formação e as práticas profissionais dos psicólogos, a fim de investir no aprofundamento e na discussão das questões destacadas por essa pesquisa. É primordial que haja o estabelecimento do compromisso social desses profissionais psicólogos, a partir da formação da profissão e da atitude ético-político; elementos fundamentais da constituição da pessoa humana e de uma comunidade e que está na origem da constante busca da efetivação da lei do SUAS.

\section{Referências}

Araujo, F. I. C. (2010). “...Mas a gente não sabe que roupa deve usar...”: um estudo sobre a prática do psicólogo no Centro de Referência de Assistência Social. Dissertação de Mestrado, Pontifícia Universidade Católica de São Paulo, São Paulo.

Bello, A. A. (2014). A Paixão pela verdade. Curitiba: Juruá.

Berger, P., \& Luckmann, T. (1984). A construção social da Realidade. Petrópolis: Vozes.

Botarelli, A. (2008). O psicólogo nas políticas de proteção social: uma análise dos sentidos e da práxis. Tese de doutorado, Pontifícia Universidade Católica de São Paulo, São Paulo.

Brasil. Ministério do Desenvolvimento Social e Combate à Fome (MDS). Secretaria Nacional de Assistência Social. (2005). Norma Operacional Básica da Assistência SocialNOB/SUAS. Brasília. 
Brasil. Ministério do Desenvolvimento Social e Combate à Fome (MDS). Secretaria Nacional de Assistência Social. (2006). Norma Operacional Básica de Recursos Humanos do SUAS - NOB-RH/SUA. Brasília.

Brasil. Ministério Do Desenvolvimento Social e Combate à Fome (MDS). Secretaria Nacional de Assistência Social. (2006a) Proteção Básica do Sistema Único de Assistência Social: Orientações e Técnicas para o Centro de Referência de Assistência Social. Brasília.

Brasil. Ministério do Desenvolvimento Social e Combate à Fome (MDS). Secretaria Nacional de Assistência Social. (2009). Orientações Técnicas. Centro de Referência da Assistência Social - CRAS. Brasília.

Brasil. Ministério da educação. Conselho nacional de educação. Câmara de educação superior. (2011). Resolução Nº 5, de 15 de Março. Diretrizes Curriculares Nacionais para os cursos de graduação em Psicologia, Brasília.

Conselho Federal de Psicologia (2007). Referências técnicas para atuação do(a) psicólogo(a) no CRAS/SUAS. Brasília.

Conselho Regional de Psicologia - $4^{\text {a }}$ Região (2011). A Psicologia e o Trabalho no CRAS. Belo Horizonte.

Ferreira Neto, J. L. (2004). A formação do Psicólogo: clínica, social e mercado. São Paulo: Escuta.

Ferreira Neto, J. L. (2011). Psicologia, Políticas Públicas e o SUS. Belo Horizonte: Escuta.

Giorgi, A. (2001). Método Psicológico Fenomenológico: alguns tópicos teóricos e práticos. Revista Educação, 24(4), 133-150.

Giorgi, A., \& Sousa, D. (2010). Método Fenomenológico da investigação em Psicologia. Lisboa: Fim de Século.

Goto, T. A. \& Almeida, B. P. (2011). Intervenção e cuidado com crianças e adolescentes vitimizadas: atuação do psicólogo no Programa Sentinela (CREAS) em Poços de Caldas (MG). Mudanças - Psicologia da Saúde, 19(1-2), 89-98.

Goto, T. A., \& Mota, S. T. (2009). Plantão psicológico no CRAS em Poços de Caldas. Fractal: Revista de Psicologia, 21(3), 521-530.

Goto, T. A., \& Ribeiro, M. E. (2012). Psicologia no Sistema Único de Assistência Social: Uma Experiência de Clínica Ampliada e Intervenção em Crise. Gerais: Revista Interinstitucional de Psicologia, 5(1), 184-194.

Martins, J., \& Bicudo, M. A. V. (2005). A pesquisa qualitativa em psicologia: fundamentos e recursos básicos. São Paulo: Centauro.

Nasser, A. C. (2008). A pesquisa qualitativa: enfoques epistemológicos e metodológicos. Petrópolis: Vozes.

Ribeiro, M. E. (2013). Psicologia no sistema único de assistência social: reflexões críticas sobre as ações e dilemas profissionais. Dissertação de Mestrado, Pontifícia Universidade Católica de Campinas, Campinas/SP.

Stein, E. (1999). A Mulher. Sua missão, segundo a natureza e a graça. Bauru, EDUSC.
Tatyanne Couto Flor - Aluna do Curso de Graduação em Psicologia da Universidade Federal de Uberlândia, bolsista de Iniciação Científica da Capes (2012-2013).

E-mail: tatyannecouto@yahoo.com.br

Tommy Akira Goto - Professor Adjunto II da Universidade Federal de Uberlândia, Doutor em Psicologia Clínica (PUC-Campinas), Mestre em Ciências da Religião (Universidade Metodista de São Paulo), Co-Presidente da Associação Brasileira de Psicologia Fenomenológica (ABRAPFE), Membro-colaborador do Circulo Latinoamericano de Fenomenologia (CLAFEN), Membro-assistente da Sociedad Iberoamericana de Estudios Heideggerianos (SIEH). Av. Maranhão, s/n - Bloco 2C, sala 2C40, Umuarama, Uberlândia/MG, CEP: 38.405-318.

E-mail:prof-tommy@hotmail.com

Recebido em 16.02.2014 Primeira Decisão Editorial em 10.06.2014 Segunda Decisão Editorial em 16.08.2014 Aceito em 31.01.2015 